\title{
Article \\ Role of ANGPTL8 in NAFLD Improvement after Bariatric
Surgery in Experimental and Human Obesity
}

\author{
Carolina M. Perdomo ${ }^{1}$, Javier Gómez-Ambrosi ${ }^{2,3,4} \oplus$, Sara Becerril ${ }^{2,3,4}$, Víctor Valentí ${ }^{3,4,5}$, Rafael Moncada ${ }^{3,4,6}$, \\ Eva M. Fernández-Sáez ${ }^{2}$, Leire Méndez-Giménez ${ }^{2}$, Silvia Ezquerro ${ }^{2}$, Victoria Catalán ${ }^{2,3,4}$ (), Camilo Silva ${ }^{1,2,3}$,

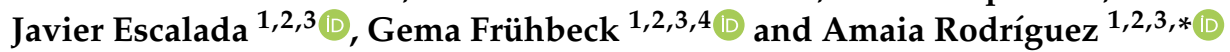

1 Department of Endocrinology \& Nutrition, Clínica Universidad de Navarra, 31008 Pamplona, Spain; cperdomo@unav.es (C.M.P.); csilvafr@unav.es (C.S.); fescalada@unav.es (J.E.); gfruhbeck@unav.es (G.F.)

2 Metabolic Research Laboratory, Clínica Universidad de Navarra, 31008 Pamplona, Spain; jagomez@unav.es (J.G.-A.); sbecman@unav.es (S.B.); efernandezs.1@alumni.unav.es (E.M.F.-S.); lmgimenezde@gmail.com (L.M.-G.); silvia_ezquerro@hotmail.com (S.E.); vcatalan@unav.es (V.C.)

3 CIBER Fisiopatología de la Obesidad y Nutrición (CIBEROBN), Instituto de Salud Carlos III, 28029 Madrid, Spain; vvalenti@unav.es (V.V.); rmoncada@unav.es (R.M.)

4 Obesity and Adipobiology Group, Instituto de Investigación Sanitaria de Navarra (IdiSNA), 31008 Pamplona, Spain

5 Department of Surgery, Clínica Universidad de Navarra, 31008 Pamplona, Spain

6 Department of Anesthesia, Clínica Universidad de Navarra, 31008 Pamplona, Spain

* Correspondence: arodmur@unav.es; Tel.: +34-948-42-56-00 (ext. 80-3357)

\section{check for}

updates

Citation: Perdomo, C.M.;

Gómez-Ambrosi, J.; Becerril, S.; Valentí,

V.; Moncada, R.; Fernández-Sáez, E.M.;

Méndez-Giménez, L.; Ezquerro, S.;

Catalán, V.; Silva, C.; et al. Role of

ANGPTL8 in NAFLD Improvement

after Bariatric Surgery in

Experimental and Human Obesity.

Int. J. Mol. Sci. 2021, 22, 12945.

https://doi.org/10.3390/ijms222312945

Academic Editor: Yoshio Sumida

Received: 5 November 2021

Accepted: 29 November 2021

Published: 30 November 2021

Publisher's Note: MDPI stays neutral with regard to jurisdictional claims in published maps and institutional affiliations.

Copyright: (c) 2021 by the authors. Licensee MDPI, Basel, Switzerland. This article is an open access article distributed under the terms and conditions of the Creative Commons Attribution (CC BY) license (https:// creativecommons.org/licenses/by/ $4.0 /)$.

\begin{abstract}
Angiopoietin-like protein 8 (ANGPTL8) is an hepatokine altered in several metabolic conditions, such as obesity, type 2 diabetes, dyslipidemia and nonalcoholic fatty liver disease (NAFLD). We sought to explore whether ANGPTL8 is involved in NAFLD amelioration after bariatric surgery in experimental models and patients with severe obesity. Plasma ANGPTL8 was measured in 170 individuals before and 6 months after bariatric surgery. Hepatic ANGPTL8 expression was evaluated in liver biopsies of patients with severe obesity undergoing bariatric surgery with available liver pathology analysis $(n=75)$, as well as in male Wistar rats with diet-induced obesity subjected to sham operation, sleeve gastrectomy or Roux-en-Y gastric bypass (RYGB) $(n=65)$. The effect of ANGPTL8 on lipogenesis was assessed in human HepG2 hepatocytes under palmitate-induced lipotoxic conditions. Plasma concentrations and hepatic expression of ANGPTL8 were increased in patients with obesity-associated NAFLD in relation to the degree of hepatic steatosis. Sleeve gastrectomy and RYGB improved hepatosteatosis and reduced the hepatic ANGPTL8 expression in the preclinical model of NAFLD. Interestingly, ANGPTL8 inhibited steatosis and expression of lipogenic factors (PPARG2, SREBF1, MOGAT2 and DGAT1) in palmitate-treated human hepatocytes. Together, ANGPTL8 is involved in the resolution of NAFLD after bariatric surgery partially by the inhibition of lipogenesis in steatotic hepatocytes.
\end{abstract}

Keywords: NAFLD; obesity; bariatric surgery; lipogenesis; angiopoietin-like protein 8

\section{Introduction}

Nonalcoholic fatty liver disease (NAFLD) is the most common cause of chronic liver disease and comprises a spectrum of liver disorders ranging from simple steatosis to nonalcoholic steatohepatitis (NASH), fibrosis and cirrhosis [1]. The incidence of NAFLD is rising due to the pandemic spread of obesity and type 2 diabetes (T2D). In this regard, the global prevalence of NAFLD in the general population is $24 \%$ [2], increasing to $75-90 \%$ and $55 \%$ in patients with severe obesity and T2D, respectively [3,4]. Bariatric surgery induces a long-term maintenance of weight loss, along with the improvement of insulin resistance and T2D remission, in patients with severe obesity $[5,6]$. Moreover, bariatric surgery has been proposed as a therapeutic option to reduce liver injury in those patients with obesity who have been diagnosed for NAFLD and are unresponsive to lifestyle interventions and 
pharmacotherapy $[7,8]$. Sleeve gastrectomy and Roux-en-Y gastric bypass (RYGB), the most commonly used bariatric surgical procedures, appear to be equally efficacious in the improvement of liver transaminases and histological lesions in patients with obesity and NAFLD [9]. Nonetheless, solid and mechanistic data on the comparative effects of these techniques on NAFLD amelioration are still needed.

Angiopoietin-like protein 8 (ANGPTL8), also known as lipasin, RIFL, C19orf80, TD26 or betatrophin, is a nutritionally-regulated hepatokine that is downregulated during fasting and upregulated after feeding [10]. Loss- and gain-of-function studies on mice revealed that ANGPTL8 constitutes a critical regulator of lipid metabolism. Adenoviral overexpression of the ANGPTL8 gene in mice results in an increase in plasma triacylglycerol (TG) levels [10] and, consistently, ANGPTL8-knockout mice exhibit low TG concentrations [11,12]. In humans, ANGPTL8 interacts with ANGPTL3 or ANGPTL4 to inhibit LPL activity $[10,13]$ and several ANGPTL8 gene variants have been linked to lipid alterations [14-16]. Interestingly, serum ANGPTL8 concentrations are decreased in several metabolic conditions, such as obesity, T2D or dyslipidemia [17-19] and increase after bariatric surgery [20], although contradictory results have been published [21]. By contrast, increased circulating and hepatic expression of ANGPTL8 levels are positively associated with different stages of NAFLD [22-25]. In this context, the aim of the present study was to evaluate whether ANGPTL8 is associated with the improvement of hepatic steatosis after sleeve gastrectomy and RYGB in a cohort of patients with severe obesity and different degrees of insulin resistance, as well as in experimental models of diet-induced obesity. Moreover, the direct effects of ANGPTL8 on key regulatory molecules involved in lipogenesis were also studied in vitro in human HepG2 hepatocytes under palmitic acid-induced lipotoxic conditions.

\section{Results}

2.1. Prevalence of NAFLD and Metabolic Improvement after Bariatric Surgery in the Studied Population

Anthropometric and clinical variables of the patients with severe obesity included in the study are shown in Table 1. As expected, all indices of adiposity (body mass index (BMI), waist circumference, body fat percentage and serum leptin levels) were higher $(p<0.0001)$ in participants with severe obesity compared with normal-weight controls. Increased $(p<0.05)$ markers of insulin resistance, evidenced by glycemia and insulinemia at baseline levels and $2 \mathrm{~h}$ after an oral glucose tolerance test (OGTT), homeostasis model assessment (HOMA), quantitative insulin sensitivity check index (QUICKI) and adipocyte insulin resistance index (Adipo-IR), were detected in patients with impaired glucose tolerance (IGT) and T2D compared with those with normoglycemia (NG). A more detrimental lipid profile, systemic inflammation and hepatic function were also detected in patients with insulin resistance. The prevalence of biopsy-proven NAFLD in our patients with severe obesity was $80.6 \%$, being higher $(p<0.0001)$ in men $(95.0 \%)$ than in women $(73.8 \%)$. Biopsy-proven NASH was detected in $41.9 \%$ of the total sample, and fibrosis was found in $23.2 \%$ of liver specimens. Individuals with insulin resistance exhibited higher $(p<0.05)$ prevalence rates of NAFLD (NG 66.0\%, IGT 86.4\% and T2D 94.5\%) and NASH (NG 34.0\%, IGT 45.9\% and T2D 48.0\%). No patient had evidence of established cirrhosis. After an average of 6 months after bariatric surgery, patients with severe obesity undergoing sleeve gastrectomy or RYGB experienced a profound decrease in body weight, whole-body adiposity and leptinemia and an improvement in insulin sensitivity, as well as a decrease in $\gamma$-glutamyltransferase $(\gamma$-GT) levels (Table 2). A better lipid profile and an improved systemic inflammation was observed in patients with severe obesity submitted to RYGB compared to those undergoing sleeve gastrectomy.

\subsection{Plasma Concentrations of ANGPTL8 Are Increased in Obesity-Associated NAFLD}

Obesity was associated with low plasma ANGPTL8 concentrations (normal weight $32.45 \pm 5.57$ vs. obesity $19.69 \pm 1.49 \mathrm{ng} / \mathrm{mL}, p=0.004$ ), regardless of the degree of insulin resistance (Figure 1a). Biopsy-proven NAFLD in patients with obesity was re- 
lated to increased circulating levels of ANGPTL8 (normal liver $11.94 \pm 1.60$ vs. NAFLD $20.00 \pm 1.96 \mathrm{ng} / \mathrm{mL}, p=0.003$ ) in both stages of NAFLD and NASH (Figure 1b). Plasma ANGPTL8 levels were positively correlated with HDL cholesterol concentrations $(\mathrm{r}=0.24$, $p=0.004)$, while negatively correlated with hepatic function marker $\gamma$-GT $(\mathrm{r}=-0.24$, $p=0.019$ ) after age and sex adjustments. Multivariate analyses were performed in order to detect the association between plasma ANGPTL8 with variables related to insulin resistance (Model I) and liver function and fat percentage (Model II) (Table S2). Both HOMA and $\gamma$-GT contributed independently to circulating ANGPTL8 after controlling for age, sex and BMI. Six months after bariatric surgery, an increase in plasma ANGPTL8 was observed in patients with obesity submitted to sleeve gastrectomy (pre-surgery $9.34 \pm 0.94$ vs. post-surgery $10.85 \pm 1.13 \mathrm{ng} / \mathrm{mL}, p<0.05$ ) and RYGB (pre-surgery $20.76 \pm 3.53$ vs. post-surgery $47.53 \pm 5.47 \mathrm{ng} / \mathrm{mL}, p<0.001)$.

Table 1. Clinical characteristics of the participants enrolled in the study.

\begin{tabular}{|c|c|c|c|c|c|}
\hline & Lean & Obese NG & Obese IGT & Obese T2D & $p$ \\
\hline$n$ & 30 & 48 & 47 & 45 & - \\
\hline Sex (male/female) & $16 / 14$ & $17 / 31$ & $17 / 30$ & $20 / 25$ & 0.199 \\
\hline Age (years) & $43 \pm 3$ & $40 \pm 2$ & $44 \pm 2$ & $48 \pm 2^{b}$ & 0.031 \\
\hline $\mathrm{BMI}\left(\mathrm{kg} / \mathrm{m}^{2}\right)$ & $22.6 \pm 0.5$ & $44.5 \pm 1.3^{\mathrm{a}}$ & $43.2 \pm 0.9^{\mathrm{a}}$ & $45.4 \pm 1.4^{\mathrm{a}}$ & $<0.0001$ \\
\hline Body fat $(\%)$ & $21.2 \pm 1.4$ & $50.7 \pm 0.9^{\mathrm{a}}$ & $51.0 \pm 1.3^{\mathrm{a}}$ & $50.1 \pm 1.2^{\mathrm{a}}$ & $<0.0001$ \\
\hline Waist circumference $(\mathrm{cm})$ & $77 \pm 3$ & $125 \pm 2^{a}$ & $125 \pm 2^{\mathrm{a}}$ & $132 \pm 3^{a}$ & $<0.0001$ \\
\hline Glucose $(\mathrm{mg} / \mathrm{dL})$ & $87 \pm 2$ & $92 \pm 1$ & $105 \pm 1^{\mathrm{a}, \mathrm{b}}$ & $142 \pm 9^{a, b}$ & $<0.0001$ \\
\hline Glucose 2-h OGTT (mg/dL) & - & $121 \pm 4$ & $154 \pm 5^{b}$ & $250 \pm 16^{b}$ & $<0.0001$ \\
\hline Insulin $(\mu \mathrm{U} / \mathrm{mL})$ & $5.7 \pm 0.6$ & $20.9 \pm 2.7^{\mathrm{a}}$ & $19.6 \pm 1.7^{\mathrm{a}}$ & $26.3 \pm 3.1^{\mathrm{a}}$ & $<0.0001$ \\
\hline Insulin 2-h OGTT $(\mu \mathrm{U} / \mathrm{mL})$ & - & $97.0 \pm 9.5$ & $141.1 \pm 12.4^{b}$ & $133.3 \pm 19.2^{b}$ & 0.034 \\
\hline HOMA & $1.2 \pm 0.1$ & $4.3 \pm 0.4$ & $5.2 \pm 0.5^{\mathrm{a}}$ & $9.2 \pm 1.7^{\mathrm{a}, \mathrm{b}}$ & $<0.0001$ \\
\hline QUICKI & $0.38 \pm 0.01$ & $0.32 \pm 0.01^{\mathrm{a}}$ & $0.31 \pm 0.01^{\mathrm{a}}$ & $0.30 \pm 0.01^{\mathrm{a}, \mathrm{b}}$ & $<0.0001$ \\
\hline FFA (mmol/L) & $15.7 \pm 0.1$ & $16.7 \pm 1.1$ & $22.5 \pm 2.2$ & $28.9 \pm 4.0^{\mathrm{a}, \mathrm{b}}$ & 0.001 \\
\hline Glycerol (mg/dL) & $18.2 \pm 3.5$ & $19.8 \pm 2.1$ & $22.1 \pm 2.5$ & $21.9 \pm 2.3$ & 0.591 \\
\hline Adipo-IR index & $20.2 \pm 3.4$ & $71.3 \pm 7.7$ & $98.9 \pm 13.7$ & $188.4 \pm 36.3^{\mathrm{a}, \mathrm{b}}$ & $<0.0001$ \\
\hline Triacylglycerol (mg/dL) & $70 \pm 5$ & $111 \pm 7^{\mathrm{a}}$ & $132 \pm 11^{\mathrm{a}}$ & $147 \pm 11^{\mathrm{a}, \mathrm{b}}$ & $<0.0001$ \\
\hline Total cholesterol (mg/dL) & $186 \pm 7$ & $191 \pm 4$ & $203 \pm 6$ & $198 \pm 6$ & 0.234 \\
\hline LDL cholesterol (mg/dL) & $110 \pm 6$ & $118 \pm 3$ & $127 \pm 5$ & $116 \pm 5$ & 0.145 \\
\hline HDL cholesterol (mg/dL) & $61 \pm 3$ & $50 \pm 4$ & $49 \pm 2^{a}$ & $44 \pm 2^{\mathrm{a}}$ & 0.001 \\
\hline $\mathrm{CRP}(\mathrm{mg} / \mathrm{L})$ & $1.8 \pm 0.3$ & $8.3 \pm 1.1$ & $9.5 \pm 1.5^{\mathrm{a}}$ & $8.8 \pm 1.8^{\mathrm{a}}$ & 0.035 \\
\hline Uric acid (mg/dL) & $4.3 \pm 0.2$ & $5.7 \pm 0.2^{\mathrm{a}}$ & $5.9 \pm 0.2^{\mathrm{a}}$ & $6.0 \pm 0.2^{\mathrm{a}}$ & 0.001 \\
\hline Leptin $(\mathrm{ng} / \mathrm{mL})$ & $6.1 \pm 0.7$ & $45.4 \pm 3.2^{\mathrm{a}}$ & $48.9 \pm 3.6^{\mathrm{a}}$ & $46.0 \pm 5.8^{a}$ & $<0.0001$ \\
\hline AST (IU/L) & $13 \pm 1$ & $16 \pm 1$ & $17 \pm 1$ & $17 \pm 1$ & 0.244 \\
\hline ALT (IU /L) & $10 \pm 2$ & $21 \pm 2$ & $28 \pm 2^{a}$ & $27 \pm 2^{\mathrm{a}}$ & $<0.0001$ \\
\hline Alkaline phosphatase (IU/L) & $86 \pm 5$ & $68 \pm 5$ & $77 \pm 6$ & $73 \pm 5$ & 0.334 \\
\hline$\gamma-\mathrm{GT}(\mathrm{IU} / \mathrm{L})$ & $11 \pm 1$ & $21 \pm 2$ & $29 \pm 4^{\mathrm{a}}$ & $30 \pm 4^{\mathrm{a}}$ & 0.015 \\
\hline Daily alcohol intake $(\mathrm{g})$ & $0.0 \pm 0.0$ & $1.1 \pm 0.9$ & $3.6 \pm 2.7$ & $4.6 \pm 2.7$ & 0.576 \\
\hline Antihypertensive therapy, n (\%) & $0(0 \%)$ & $11(23 \%)$ & $17(32 \%)$ & $19(49 \%)$ & 0.003 \\
\hline Antidiabetic therapy, $\mathrm{n}(\%)$ & $0(0 \%)$ & $2(4 \%)$ & $1(2 \%)$ & $20(51 \%)$ & $<0.0001$ \\
\hline Lipid-lowering therapy, n (\%) & $0(0 \%)$ & $6(13 \%)$ & $7(15 \%)$ & $11(28 \%)$ & 0.061 \\
\hline
\end{tabular}

NG, normoglycemia; IGT, impaired glucose tolerance; T2D, type 2 diabetes; BMI, body mass index; OGTT, oral glucose tolerance test; HOMA, homeostasis model assessment; QUICKI, quantitative insulin sensitivity check index; FFA, free fatty acids; Adipo-IR, adipocyte insulin resistance index; CRP, high-sensitivity C-reactive protein; AST, aspartate aminotransferase; ALT, alanine aminotransferase; $\gamma$-GT, $\gamma$-glutamyltransferase. Differences between groups were analyzed by one-way ANOVA followed by a Scheffe's test or $\chi^{2}$ test, where appropriate. Bold values denote statistically significant $p$ values. ${ }^{\mathrm{a}} p<0.05$ vs. normal-weight individuals; ${ }^{\mathrm{b}} p<0.05$ vs. obese NG patients.

\subsection{Hepatic Expression of ANGTL8 Is Upregulated in Patients with Morbid Obesity and NAFLD in Relation to Their Degree of Liver Steatosis}

The presence of ANGPTL8 in the human liver was evaluated in liver biopsies $(n=74)$ obtained from patients with morbid obesity by immunohistochemistry and real-time PCR. The tissue distribution of ANGPTL8 was mainly detected in hepatocytes, and the immunostaining was markedly increased in liver sections obtained from patients with 
insulin resistance (Figure 2a) and NAFLD (Figure 2b). Accordingly, the transcription of the ANGPTL8 gene was upregulated in parallel with the impairment of insulin sensitivity (Figure 2c) and hepatic function (Figure 2d). Consistent with these findings, ANGPTL 8 mRNA levels were increased according to the degree of steatosis (Figure 2e) and were positively correlated with the NAFLD activity score (NAS) (Figure 2f). Moreover, multiple regression analysis revealed that the liver steatosis contributed independently to $41.8 \%$ of variation in hepatic ANGPTL8 transcripts after controlling for age, sex and BMI.

Table 2. Effect of weight loss induced by bariatric surgery on clinical characteristics of patients with morbid obesity.

\begin{tabular}{|c|c|c|c|c|c|c|}
\hline & \multicolumn{3}{|c|}{ Sleeve Gastrectomy $(n=34)$} & \multicolumn{3}{|c|}{ Roux-en-Y Gastric Bypass $(n=41)$} \\
\hline & Pre-Surgery & Post-Surgery & $p$ & Pre-Surgery & Post-Surgery & $p$ \\
\hline Sex (male/female) & $10 / 24$ & $10 / 24$ & - & $15 / 26$ & $15 / 26$ & - \\
\hline BMI $\left(\mathrm{kg} / \mathrm{m}^{2}\right)$ & $41.0 \pm 1.7$ & $31.1 \pm 1.6$ & $<0.0001$ & $44.7 \pm 0.8$ & $31.9 \pm 0.6$ & $<0.0001$ \\
\hline Body fat $(\%)$ & $50.9 \pm 1.2$ & $39.5 \pm 1.8$ & $<0.0001$ & $50.7 \pm 0.8$ & $38.1 \pm 1.0$ & $<0.0001$ \\
\hline Waist circumference $(\mathrm{cm})$ & $120 \pm 3$ & $98 \pm 3$ & $<0.0001$ & $127 \pm 2$ & $100 \pm 2$ & $<0.0001$ \\
\hline Glucose $(\mathrm{mg} / \mathrm{dL})$ & $106 \pm 9$ & $92 \pm 4$ & 0.022 & $115 \pm 5$ & $95 \pm 4$ & $<0.0001$ \\
\hline Insulin $(\mu \mathrm{U} / \mathrm{mL})$ & $30.9 \pm 6.6$ & $10.0 \pm 1.6$ & 0.005 & $23.0 \pm 3.3$ & $8.6 \pm 1.1$ & $<0.0001$ \\
\hline HOMA & $8.3 \pm 2.1$ & $2.1 \pm 0.4$ & 0.011 & $6.2 \pm 1.3$ & $2.3 \pm 0.6$ & $<0.0001$ \\
\hline QUICKI & $0.30 \pm 0.01$ & $0.36 \pm 0.01$ & $<0.0001$ & $0.31 \pm 0.01$ & $0.36 \pm 0.01$ & $<0.0001$ \\
\hline FFA $(\mathrm{mmol} / \mathrm{L})$ & $18.8 \pm 1.2$ & $14.3 \pm 1.5$ & 0.052 & $21.5 \pm 2.2$ & $13.2 \pm 1.0$ & 0.001 \\
\hline Glycerol (mg/dL) & $19.4 \pm 2.2$ & $14.0 \pm 0.8$ & 0.043 & $22.4 \pm 2.1$ & $12.9 \pm 1.3$ & 0.001 \\
\hline Adipo-IR index & $138.7 \pm 40.0$ & $32.6 \pm 6.3$ & 0.020 & $91.9 \pm 12.7$ & $28.7 \pm 5.6$ & $<0.0001$ \\
\hline Triacylglycerol (mg/dL) & $110 \pm 15$ & $98 \pm 10$ & 0.380 & $136 \pm 9$ & $90 \pm 4$ & $<0.0001$ \\
\hline Total cholesterol (mg/dL) & $185 \pm 8$ & $186 \pm 9$ & 0.919 & $199 \pm 5$ & $158 \pm 4$ & $<0.0001$ \\
\hline LDL cholesterol (mg/dL) & $115 \pm 7$ & $119 \pm 7$ & 0.576 & $122 \pm 5$ & $92 \pm 3$ & $<0.0001$ \\
\hline HDL cholesterol (mg/dL) & $47 \pm 3$ & $52 \pm 3$ & 0.111 & $49 \pm 3$ & $48 \pm 1$ & 0.666 \\
\hline $\mathrm{CRP}(\mathrm{mg} / \mathrm{L})$ & $4.6 \pm 1.5$ & $3.0 \pm 1.2$ & 0.252 & $7.9 \pm 1.1$ & $2.4 \pm 0.3$ & $<0.0001$ \\
\hline Uric acid (mg/dL) & $5.0 \pm 0.3$ & $4.7 \pm 0.3$ & 0.203 & $6.1 \pm 0.2$ & $4.9 \pm 0.1$ & $<0.0001$ \\
\hline Leptin $(\mathrm{ng} / \mathrm{mL})$ & $77.0 \pm 12.7$ & $25.3 \pm 5.9$ & 0.004 & $51.0 \pm 4.6$ & $16.2 \pm 2.5$ & $<0.0001$ \\
\hline AST (IU/L) & $17 \pm 1$ & $17 \pm 1$ & 0.983 & $18 \pm 1$ & $18 \pm 1$ & 0.849 \\
\hline ALT (IU /L) & $22 \pm 3$ & $19 \pm 2$ & 0.318 & $27 \pm 2$ & $26 \pm 2$ & 0.606 \\
\hline Alkaline phosphatase (IU/L) & $64 \pm 6$ & $65 \pm 5$ & 0.916 & $82 \pm 5$ & $84 \pm 5$ & 0.529 \\
\hline$\gamma-\mathrm{GT}(\mathrm{IU} / \mathrm{L})$ & $29 \pm 6$ & $22 \pm 4$ & 0.027 & $24 \pm 3$ & $14 \pm 2$ & $<0.0001$ \\
\hline Antihypertensive therapy, $n(\%)$ & $15(44 \%)$ & $12(34 \%)$ & 0.001 & $17(41 \%)$ & $9(22 \%)$ & 0.011 \\
\hline Antidiabetic therapy, $n(\%)$ & $8(24 \%)$ & $5(15 \%)$ & 0.085 & $12(29 \%)$ & $4(10 \%)$ & 0.001 \\
\hline Lipid-lowering therapy, $n(\%)$ & $8(24 \%)$ & $3(9 \%)$ & 0.113 & $11(27 \%)$ & $3(7 \%)$ & 0.081 \\
\hline
\end{tabular}

BMI, body mass index; HOMA, homeostasis model assessment; QUICKI, quantitative insulin sensitivity check index; FFA, free fatty acids; Adipo-IR, adipocyte insulin resistance index; CRP, high-sensitivity C-reactive protein; AST, aspartate aminotransferase; ALT, alanine aminotransferase; $\gamma$-GT, $\gamma$-glutamyltransferase. Differences between groups were analyzed by paired two-tailed Wilcoxon $t$-test or $\chi^{2}$ test, where appropriate. Bold values denote statistically significant $p$ values.

\subsection{Increased Hepatic Expression of ANGPTL8 in a Preclinical Model of Diet-Induced Obesity Is Downregulated after Bariatric Surgery}

To corroborate the human findings regarding the potential involvement of ANGPTL8 in the improvement of NAFLD after bariatric surgery, an experimental model of dietinduced obesity submitted either to sleeve gastrectomy or RYGB was used. As expected, animals on a high-fat diet (HFD) for 4 months exhibited an increased body weight and adiposity, as well as impaired glucose tolerance and insulin resistance, compared to those fed a normal diet (ND) (Figure S1). Diet-induced obesity was also associated with impaired liver function and steatosis, evidenced by higher liver weight and serum AST levels, as well as an increased intrahepatic triacylglycerol content (all $p<0.05)$ (Figure 3a-d). Transcript levels of rat ANGPTL8 were significantly increased $(p<0.05)$ in the liver of rats with diet-induced obesity compared to lean control rats (Figure 3e). Accordingly, a strong immunostaining for the ANGPTL8 protein was observed in hepatocytes of liver sections obtained from rats fed a HFD (Figure 3f). One month after bariatric surgery, obese animals submitted either to sleeve gastrectomy or RYGB showed an improved body weight, adiposity and metabolic profile (Figure S2). Both bariatric surgical procedures 
significantly reduced serum AST and ALT transaminase levels and liver steatosis (all $p<0.05$ ) in obese rats, without changes in liver weight (Figure 3g-j). Importantly, hepatic ANGPTL8 mRNA was significantly downregulated after sleeve gastrectomy and RYGB, and a positive association of post-surgical ANGPTL8 transcript levels with liver steatosis (Figure 31) and AST ( $\mathrm{r}=0.57, p=0.002)$ was detected.

(a)

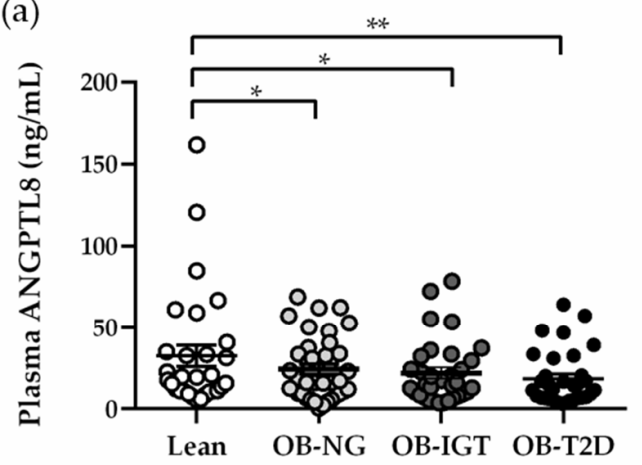

(c)

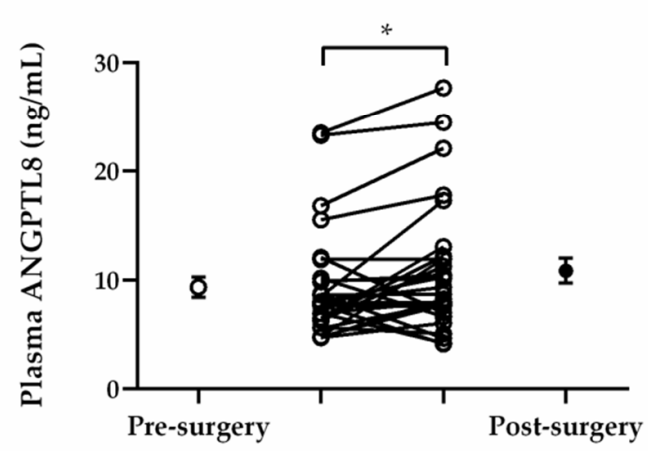

(b)

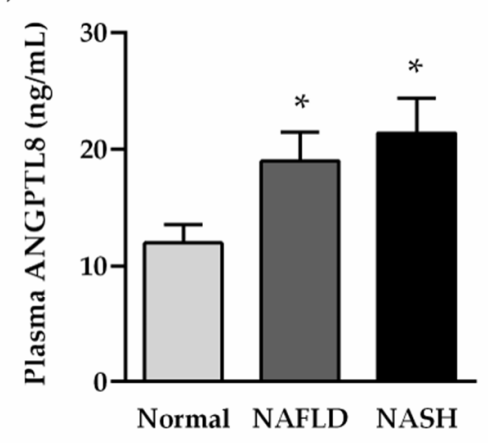

(d)

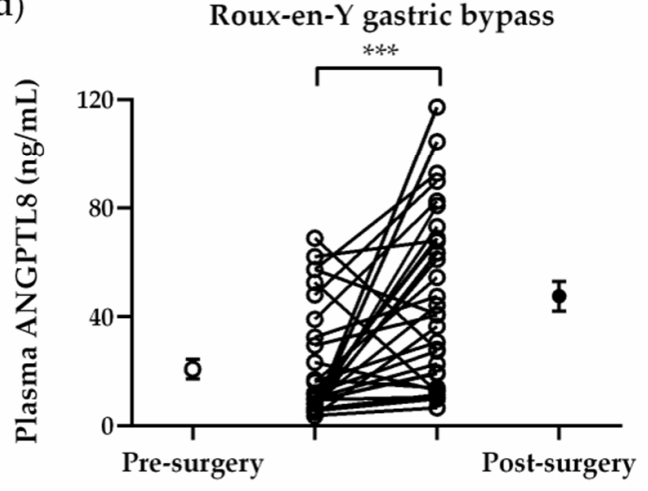

Figure 1. Effect of insulin resistance and NAFLD on plasma concentrations of ANGPTL8 in patients with severe obesity before and after bariatric surgery. Fasting plasma concentrations of ANGPTL8 according to severe obesity and insulin resistance (a) or hepatic function (b). Impact of weight loss achieved 6 months after sleeve gastrectomy (c) or RYGB (d) in plasma ANGPTL8 levels. Statistical differences were analyzed by one-way ANOVA followed by a Tukey's test or by a two-tailed paired Student's $t$-test, where appropriate. ${ }^{*} p<0.05 ;{ }^{* *} p<0.01$; ${ }^{* * *} p<0.001$ vs. patients with NG or normal liver.

\subsection{ANGPTL8 Inhibits Palmitate-Induced Lipogenesis, but Not Its Anti-Proliferative Action, in Human HepG2 Hepatocytes}

The direct effect of ANGPTL8 against lipotoxicity was tested in an in vitro model of NAFLD. Human HepG2 hepatocytes were exposed to palmitate $(200 \mu \mathrm{mol} / \mathrm{L})$ in the absence or presence of ANGPTL8 $(10 \mathrm{ng} / \mathrm{mL})$ for $24 \mathrm{~h}$. As expected, palmitate stimulation increased $(p<0.05)$ intracellular TG content (Figure 4a) and upregulated $(p<0.05)$ lipogenic transcription factors (PPARG2 and SREBF1) and enzymes (MOGAT2 and DGAT1) (Figure $4 \mathrm{~b})$ in HepG2 hepatocytes. ANGPTL8 reduced the steatosis $(p<0.05)$ and mRNA expression levels of PPARG2, SREBF1, MOGAT2 and DGAT1 lipogenic genes of palmitatetreated hepatocytes (Figure 4a,b). However, ANGPTL8 could not prevent the anti-proliferative action of palmitate in steatotic HepG2 hepatocytes, evidenced by a lower proliferation rate (Figure 4c) and decreased mRNA expression of the master regulator of hepatocyte differentiation HNF4A compared to control cells (Figure 4d). 
(a)

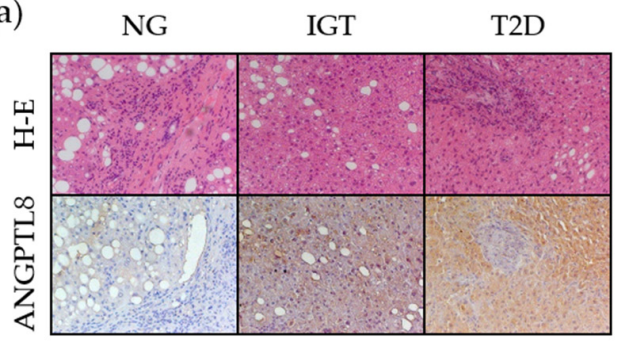

(c)

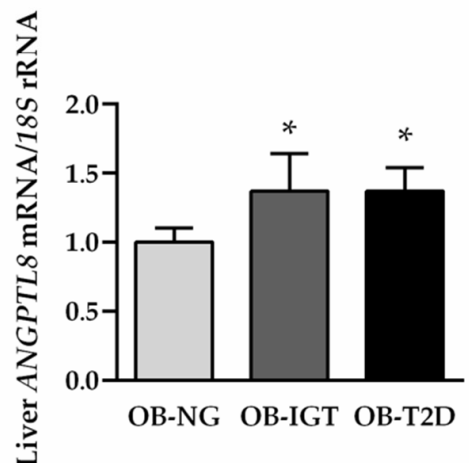

(e)

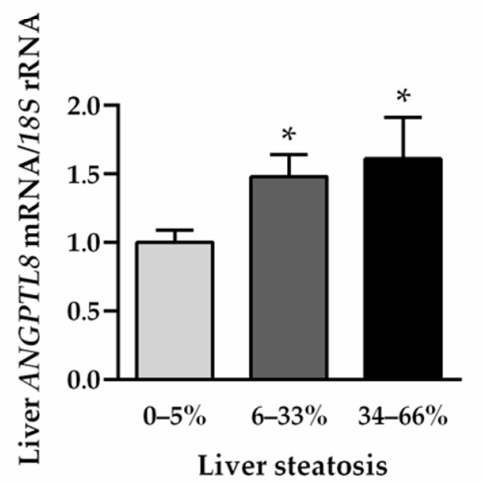

(b) Normal liver NAFLD NASH

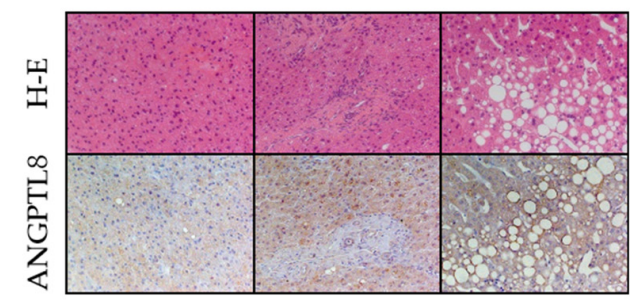

(d)

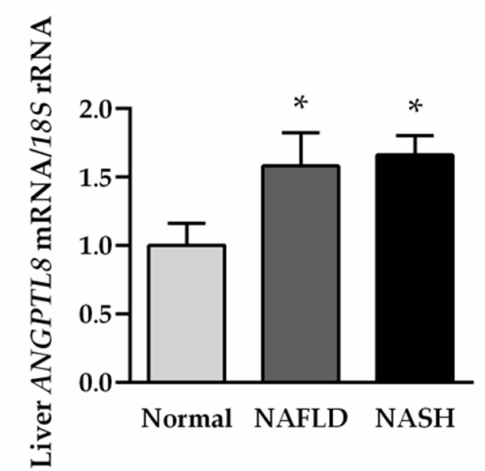

(f)

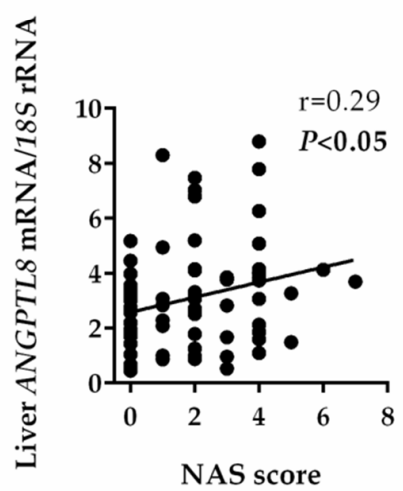

Figure 2. Hepatic ANGPTL8 expression in obesity-associated T2D and NAFLD. Liver sections obtained from patients with severe obesity classified according to their degree of insulin resistance (a) or hepatic function (b) stained with H-E (upper panels) and marked with antibodies against ANGPTL8 (lower panels) (magnification 200 $\times$ ). Bar graphs show the effect of insulin resistance (c), NAFLD (d) and the degree of liver steatosis (e) on hepatic ANGPTL8 transcripts. (f) Correlation between hepatic ANGPTL8 mRNA and NAS score. Statistical differences were analyzed by oneway ANOVA followed by a Tukey's test. ${ }^{*} p<0.05$ vs. patients with NG, normal liver or $0-5 \%$ liver steatosis. 


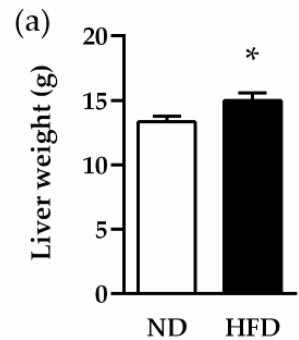

(d)

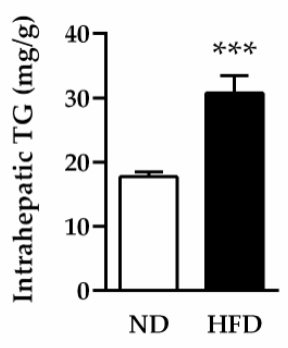

(g)

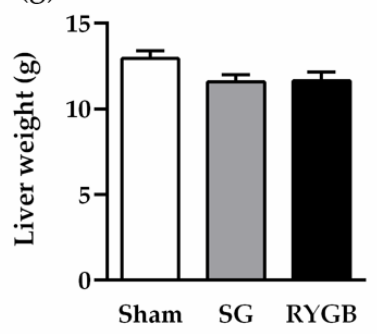

(j)

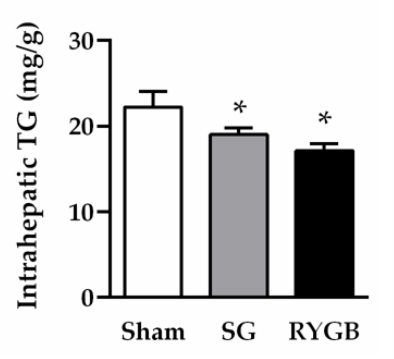

(b)

(e)
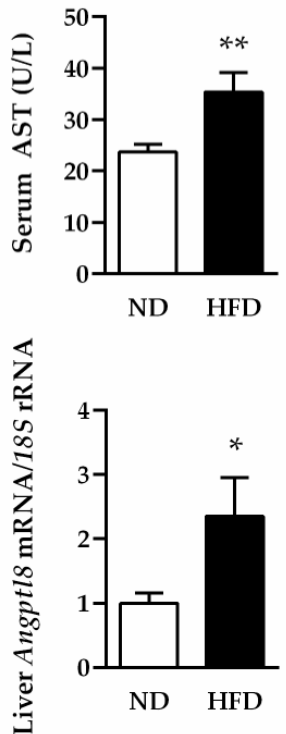

(h)

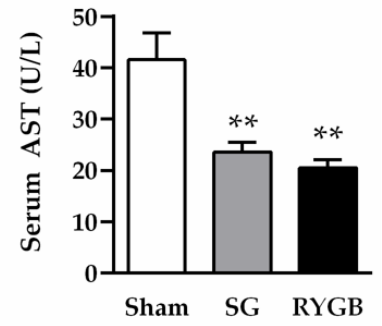

(k)

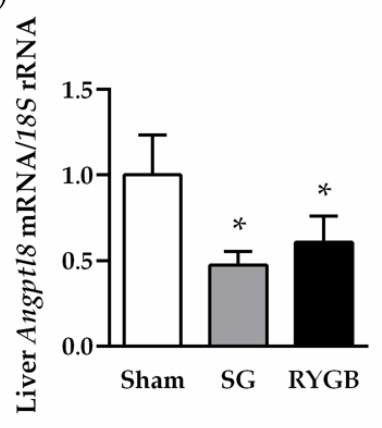

(c)

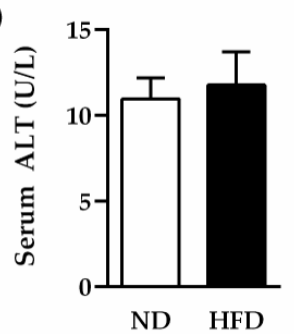

(f)

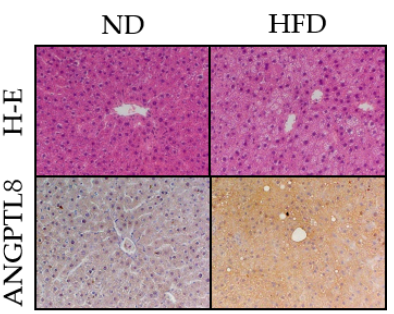

(i)

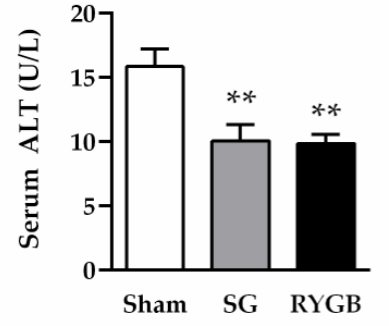

(1)

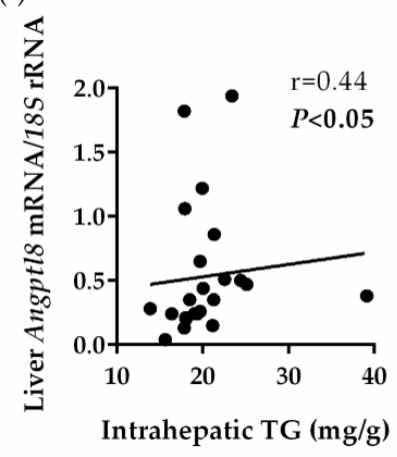

Figure 3. Hepatic expression of ANGPTL8 in rats with diet-induced obesity before and after bariatric surgery. Bar graphs show the effect of diet-induced obesity and weight loss achieved 1 month after sleeve gastrectomy (SG) or Roux-en-Y gastric bypass (RYGB) on rat liver weight (a,g), AST (b,h) and ALT (c,i) transaminase levels, intrahepatic TG content $(\mathbf{d}, \mathbf{j})$ and hepatic Angptl8 transcript levels $(\mathbf{e}, \mathbf{k})$. (f) Liver sections stained with H-E (upper panels) and marked with antibodies against ANGPTL8 (lower panels) (magnification 200x). (1) Correlation between post-surgical hepatic mRNA expression of ANGGPTL8 and intrahepatic TG. Statistical differences were analyzed by a Student's $t$-test or one-way ANOVA followed by a Tukey's test, where appropriate. ${ }^{*} p<0.05,{ }^{* *} p<0.01$ and ${ }^{* * *} p<0.001$ vs. rats fed a ND or sham-operated groups. 
(a)
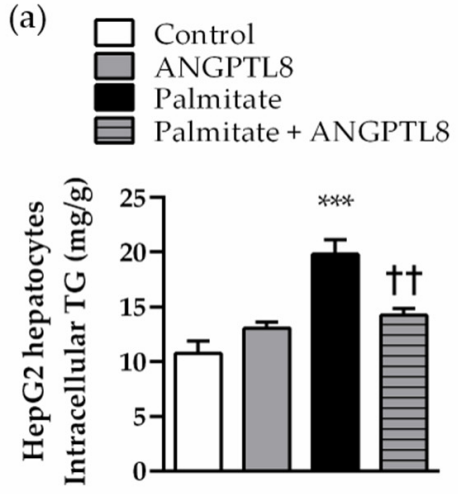

(c)

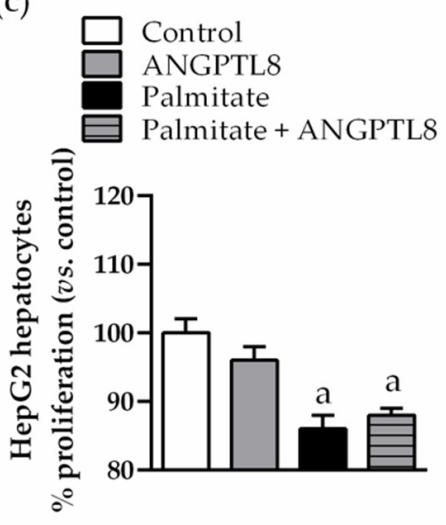

(b)
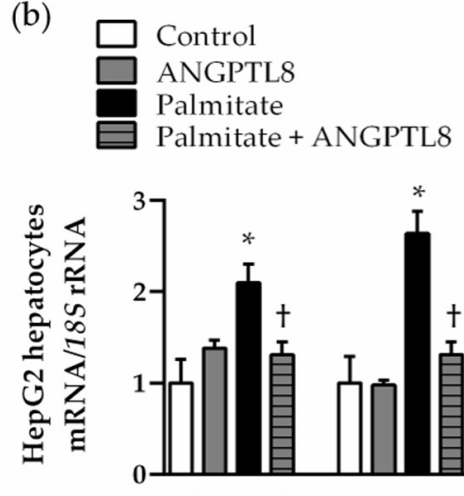

(d)
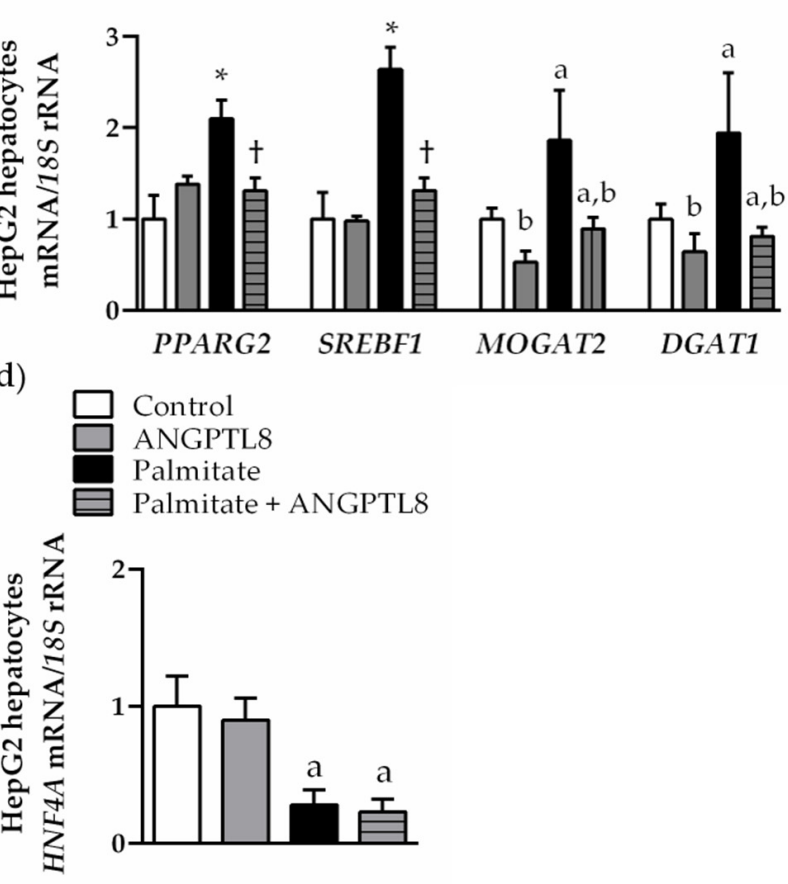

Figure 4. ANGPTL8 reversed palmitate-induced lipogenesis in human HepG2 hepatocytes. Bar graphs show the (a) intracellular triacylglycerol content and (b) mRNA expression of lipogenic transcription factors and enzymes in HepG2 hepatocytes stimulated with palmitate in the absence or presence of ANGPTL8 for $24 \mathrm{~h}$. Proliferation rate (c) and transcript levels of hepatocyte differentiation transcription factor HNF4A (d) are shown. Statistical differences were analyzed by a two-way ANOVA or a one-way ANOVA followed by Tukey's post hoc test, if an interaction between factors was detected. ${ }^{*} p<0.05 ; * * * p<0.001$ vs. unstimulated HepG2 cells; $+p<0.05 ;+\dagger p<0.01$ vs. palmitate-treated HepG2 cells; a $p<0.05$ effect of palmitate; $b p<0.05$ effect of ANGPTL8.

\section{Discussion}

ANGPTL8 is an hepatokine regulated by nutritional status that plays an important role in lipid metabolism [21]. In the fed state, hepatic expression of ANGPTL8 is increased and ANGPTL8 forms hetero-complexes with ANGPTL3 in the liver and with ANGPTL4 in the adipose tissue to inhibit LPL, an enzyme that hydrolyzes TG from chylomicrons and VLDL into FFA [26]. By contrast, during fasting, circulating ANGPTL8/ANGPTL3 complexes are reduced, thereby increasing LPL activity in peripheral tissues to ensure the energy supply [27]. ANGPTL8 is upregulated by pro-lipogenic stimuli, such as insulin or glucose, in the adipose tissue [28] but, to our knowledge, the direct action of this hepatokine on lipogenesis has not yet been explored in the liver. HepG2 hepatocytes are widely used to model human NAFLD in vitro when exposed to oleic or palmitic acid leading to steatosis and apoptosis [29]. We herein show that, in palmitate-induced human HepG2 hepatocytes, ANGPTL8 decreased intracellular TG content by downregulating the transcript levels of the lipogenic transcript factors (PPARG and SREBF1) and enzymes (MOGAT2 and DGAT1). The relationship between ANGPTL8 and NAFLD remains unclear, with controversial reports indicating increased [23,30,31] or decreased [32] circulating levels of ANGPTL8 in patients with biopsy-proven NAFLD compared with healthy volunteers. In our hands, plasma ANGPTL8 concentrations were elevated in obesity-associated NAFLD and negatively correlated with HDL cholesterol, confirming the inseparable association between ANGPTL8 and lipid disorders $[19,33]$. Furthermore, hepatic mRNA and protein expression 
of ANGPTL8 was upregulated in patients and rat models with obesity-associated NAFLD in relation to the degree of hepatic steatosis. A similar upregulation of hepatic ANGPTL8 was reported in genetically obese $o b / o b$ and $d b / d b$ mice, as well as in mice fed a high-fat or methionine-choline-deficient diet [23]. Together, the increase in ANGPTL8 seems to protect the liver against lipotoxicity partially through the direct inhibition of lipogenesis in human steatotic hepatocytes.

Bariatric surgery improves serum transaminases, NAS score and NAFLD fibrosis score in patients with severe obesity, with sleeve gastrectomy and RYGB being equally effective in ameliorating NAFLD $[9,34,35]$. In line with this observation, our data confirmed that sleeve gastrectomy and RYGB ameliorates hepatic function, as evidenced by an improved profile of AST and ALT and hepatosteatosis in an experimental model of NAFLD. Interestingly, sleeve gastrectomy and RYGB induced a downregulation of ANGPTL8 in the liver of dietinduced obese rats 1 month after surgical interventions. Moreover, post-surgical hepatic ANGPTL8 transcripts were inversely related to liver TG content and transaminase AST, supporting the hepatoprotective action of ANGPTL8 against liver steatosis. In line with this observation, metabolic adaptations after bariatric surgery include modulations in the production of hepatokines, such as fetuin-A, selenoprotein $\mathrm{P}$, adropin, sex-hormonebinding globulin (SHBG), insulin-like growth factor binding protein (IGFBP)-2 or fibroblast growth factor 21 (FGF-21), but literature on patients is scarce [36-38]. The results of the impact of bariatric surgery on hepatokine ANGPTL8 levels are not univocal. Serum ANGPTL8 levels are increased after sleeve gastrectomy [20,39], although some authors have proposed unique biphasic changes with a first prominent elevation 1 month after sleeve gastrectomy followed by a gradual decrease to reach almost baseline levels 1 year after surgery [39]. Analogously, conflicting results have been published regarding serum ANGPTL8 1 year after RYGB, with some authors observing decreased $[40,41]$, while others increased [20,42], post-surgical levels of this hepatokine. In the present study, we evaluated plasma ANGPTL8 concentrations 6 months after sleeve gastrectomy and RYGB in patients with obesity and biopsy-proven NAFLD. After this post-surgical period, an improved hepatic function evidenced by reduced $\gamma$-GT levels was observed, with similar efficacy in both bariatric procedures. Moreover, we found an elevation of ANGPTL8 levels after sleeve gastrectomy and RYGB, suggesting that increased ANGPTL8 levels might be involved in the still ongoing resolution of NAFLD in the medium term after bariatric surgery.

One limitation of the present study constitutes the use of animal models that can lead to translational discrepancies due to species-specific differences when compared to human data. Otherwise, experimental animals are invaluable resources for obesity research, especially as regards the effects of diet on metabolism and disease. In this sense, the use of rat models of diet-induced obesity leading to NAFLD avoids the high inter-individual variability found in patients due to differences in genetics, psychosocial background and pharmacological treatment.

\section{Conclusions}

In conclusion, we herein show that ANGPTL8 inhibits lipogenesis in human hepatocytes exposed to lipotoxic conditions. Moreover, circulating and hepatic ANGPTL8 expression in human and experimental obesity-associated NAFLD were increased in relation to the degree of liver steatosis, and both sleeve gastrectomy and RYGB downregulated the ANGPTL8 transcripts in the liver of preclinical models. These results support the notion that ANGPTL8 mediates, at least in part, the improvement of NAFLD after bariatric surgery via the improvement of hepatic lipid metabolism.

\section{Materials and Methods}

\subsection{Patients}

Plasma ANGPTL8 was evaluated in a cross-sectional study with 170 samples obtained from normal-weight volunteers $(n=30)$ or patients with severe obesity $(n=140)$ undergoing sleeve gastrectomy or RYGB at the Clínica Universidad de Navarra. Obe- 
sity was defined as a BMI $\geq 30 \mathrm{~kg} / \mathrm{m}^{2}$ and normal weight as a BMI $<25 \mathrm{~kg} / \mathrm{m}^{2}$. Body composition was measured by air-displacement plethysmography (Bod-Pod ${ }^{\circledR}$, COSMED, Rome, Italy). Patients with obesity were sub-classified into three groups (NG, IGT and T2D) following the criteria of the Expert Committee on the Diagnosis and Classification of Diabetes [43]. Inclusion criteria encompass a complete diagnostic work-up including physical examination, laboratory investigation, ultrasound echography and a liver biopsy consistent with the diagnosis of NAFLD. Exclusion criteria were: (i) significant alcohol abuse (average daily alcohol consumption $\geq 20 \mathrm{~g}$ for women and $\geq 30 \mathrm{~g}$ for men); (ii) the presence of a hepatitis $B$ virus surface antigen or hepatitis $C$ virus antibodies in the absence of a history of vaccination; (iii) use of medication associated with NAFLD within the past year, including amiodarone, valproate, tamoxifen, methotrexate, corticosteroids or anti-retrovirals; (iv) evidence of other specific liver diseases, such as autoimmune liver disease, haemochromatosis, Wilson's disease or $\alpha$-1-antitrypsin deficiency evaluated by antinuclear antibody, smooth muscle antibody, ferritin, $\alpha$-1-antitrypsin and ceruloplasmin levels. In the interventional study, a group of 75 patients with obesity was selected to investigate the impact of weight loss achieved 6 months after sleeve gastrectomy $(n=34)$ or RYGB $(n=41)$ on circulating ANGPTL8. Intraoperative liver biopsies were obtained from patients with severe obesity during sleeve gastrectomy or RYGB to establish a histological diagnosis of the hepatic state, but this procedure is not clinically justified in normal-weight participants. The diagnosis of NAFLD and NASH was established based on Kleiner's criteria by an expert pathologist masked to all the results of the assays [44]. Features of steatosis, lobular inflammation and hepatocyte ballooning were combined to obtain NAFLD activity score (NAS) (0-8) [44]. All reported investigations were carried out in accordance with the principles of the Declaration of Helsinki, as revised in 2013, approved by the Hospital's Ethical Committee (protocol 2017.104) and the informed consent from all volunteers was obtained.

\subsection{Experimental Animals}

Four-week-old male Wistar rats $(n=65)$ were fed ad libitum during 4 months with either a ND $(n=15)(12.1 \mathrm{~kJ}: 4 \%$ fat, $82 \%$ carbohydrate and $14 \%$ protein, diet $2014 \mathrm{~S}$, Harlan, Teklad Global Diets, Harlan Laboratories Inc., Barcelona, Spain) or a HFD ( $n=50)$ ( $23.0 \mathrm{~kJ} / \mathrm{g}$ : $59 \%$ fat, $27 \%$ carbohydrate and $14 \%$ protein, diet F3282; Bio-Serv, Frenchtown, NJ, USA). Weight-matched rats with diet-induced obesity were randomly distributed into 3 groups: (a) sleeve gastrectomy $(n=10)$; (b) RYGB $(n=6)$; and (c) sham surgery without gastric resection and intestinal bypass $(n=10)$. Anesthesia, sleeve gastrectomy and RYGB were performed according to previously described methodology [45]. Following the surgical interventions, analgesic care included a subcutaneous administration of $5 \mathrm{~mL}$ of buprenorphine $(0.03 \mathrm{mg} / \mathrm{kg}$ ) (Schering-Plough S.A., Madrid, Spain) twice daily for 3 days, as well as topical aluminum powder antiseptic spray over the surgical wound (Aluspray ${ }^{\circledR}$, Vetoquinol UK Ltd., Buckingham, UK). Rats were kept on a liquid diet with $5 \%$ glucose and $0.9 \%$ saline solution for 3 days and, thereafter, animals were fed a ND. Two weeks after surgery, oral glucose tolerance (OGTT) and intraperitoneal insulin tolerance (IPITT) tests were performed after a $12 \mathrm{~h}$ fasting period. Glucose concentrations were measured before and $15,30,60,90$ and $120 \mathrm{~min}$ after the oral glucose challenge $(2 \mathrm{~g} / \mathrm{kg}$ of body weight) or intraperitoneal insulin administration $(0.15 \mathrm{IU} / \mathrm{mL})$ with an automatic glucose sensor (Ascensia Elite, Bayer, Barcelona, Spain). Four weeks after surgical interventions, rats were killed by decapitation after an $8 \mathrm{~h}$ fast. All experimental procedures were approved by the Ethical Committee for Animal Experimentation of the University of Navarra (049/10) and conformed to the European Guidelines for the Care and Use of Laboratory Animals (directive 2010/63/EU).

\subsection{Blood Analysis}

Biochemical assays in patients [46] and experimental animals [45] were performed as previously described. The HOMA score of insulin resistance was calculated with the 
formula: fasting insulin $(\mu \mathrm{U} / \mathrm{mL}) \times$ fasting glucose $(\mathrm{mmol} / \mathrm{L}) / 22.5$. An indirect measure of insulin sensitivity was calculated by using the QUICKI index $(1 /[\log$ (fasting insulin in $\mu \mathrm{U} / \mathrm{mL})+\log ($ fasting glucose in $\mathrm{mg} / \mathrm{dL})]$. Adipo-IR index, as a surrogate of adipocyte dysfunction, was calculated as fasting FFA (mmol/L) $x$ fasting insulin (pmol/L). Intrahepatic TG content was measured by enzymatic methods, as previously described [46]. Human plasma ANGPTL8 was determined by ELISA (CSB-EL028107HU, Cusabio, Wuhan, China), with intra- and inter-assay coefficients of variation being $<8 \%$ and $<10 \%$, respectively.

\subsection{Real-Time PCR}

RNA isolation and purification from human and rat liver $(25 \mathrm{mg})$ were performed using TRIzol ${ }^{\circledR}$ Reagent (Invitrogen, Carlsbad, CA, USA) and RNeasy Mini Kit (Qiagen, Maryland, MD, USA), according to manufacturer's instructions. Transcript levels of human and rat genes encoding ANGPTL8, as well as human genes encoding PPARG2, SREBF1, MOGAT2 and DGAT1 were quantified by real-time PCR (7300 Real-Time PCR System; Applied Biosystems, Foster City, CA, USA). Primers and probes (Table S1) were designed using the software Primer Express 2.0 (Applied Biosystems) and purchased from Genosys (Sigma, St. Louis, MO, USA). Primers or TaqMan ${ }^{\circledR}$ probes encompassing fragments of the areas from the extremes of two exons were designed to ensure the detection of the corresponding transcript avoiding genomic DNA amplification. The cDNA was amplified at the following conditions: $95^{\circ} \mathrm{C}$ for $10 \mathrm{~min}$, followed by 45 cycles of $15 \mathrm{~s}$ at $95^{\circ} \mathrm{C}$ and 1 min at $59{ }^{\circ} \mathrm{C}$, using the TaqMan ${ }^{\circledR}$ Universal PCR Master Mix (Applied Biosystems). The primer and probe concentrations were 300 and $200 \mathrm{nmol} / \mathrm{L}$, respectively. All results were normalized for $18 S$ rRNA expression (Applied Biosystems), and relative quantification was calculated using the $2^{-\Delta \Delta \mathrm{Ct}}$ formula [47].

\subsection{Immunohistochemistry of ANGPTL8}

Sections of formalin-fixed paraffin-embedded human or rat liver $(4 \mu \mathrm{m})$ were used to detect ANGPTL8 by the indirect immunoperoxidase assay [46]. Slides were deparaffinized in xylene and rehydrated in graded ethanol solutions. Endogenous peroxidase activity was blocked by incubation with $3 \% \mathrm{H}_{2} \mathrm{O}_{2}$ (Sigma) in absolute methanol for 10 min at room temperature (RT), followed by washing in absolute ethanol. For epitope retrieval, sections were heated in a microwave oven for $20 \mathrm{~min}$ at $800 \mathrm{~W}$ and $400 \mathrm{~W}$ in a $10 \mathrm{mmol} / \mathrm{L}$ sodium citrate buffer ( $\mathrm{pH}$ 6.00). Nonspecific binding was blocked with $1 \%$ murine serum (Sigma) diluted in Tris-buffer saline (TBS) $(50 \mathrm{mmol} / \mathrm{L}$ Tris, $0.5 \mathrm{~mol} / \mathrm{L} \mathrm{NaCl}$; $\mathrm{pH} 7.36)$ for $1 \mathrm{~h}$ at RT. Slides were incubated overnight at $4{ }^{\circ} \mathrm{C}$ with rabbit polyclonal anti-ANGPTL8 (SAB3501080, Sigma) diluted 1:100 in TBS. After washing the slides in TBS three times (5 min each), a pure DAKO Real ${ }^{\mathrm{TM}}$ EnVision $^{\mathrm{TM}}$ anti-rabbit/mouse HRP polymer (K5007; Dako, Golstrup, Denmark) was added for $1 \mathrm{~h}$ at RT. The peroxidase reaction was visualized using a $0.5 \mathrm{mg} / \mathrm{mL}$ diaminobenzidine $(\mathrm{DAB}) / 0.03 \% \mathrm{H}_{2} \mathrm{O}_{2}$ solution diluted in $50 \mathrm{mmol} / \mathrm{L}$ Tris- $\mathrm{HCl}, \mathrm{pH} 7.36$ and Harris hematoxylin solution (Sigma) as counterstaining.

\subsection{Cell Culture and Treatment}

Human HepG2 hepatocytes (European Collection of Cell Cultures, Sigma) were seeded at $3 \times 10^{5}$ cell $/ \mathrm{cm}^{2}$ and grown in DMEM containing 10\% FBS, $25 \mathrm{mmol} / \mathrm{L}$ D-glucose and 1\% antibiotic-antimycotic (Invitrogen). Cells were serum-starved for $24 \mathrm{~h}$ and treated with palmitic acid (200 $\mu \mathrm{mol} / \mathrm{L})$ (P0500, Sigma) diluted in DMEM 5\% BSA in the presence or absence of ANGPTL8 (10 ng/mL) (10159-AN, R\&D systems) for $24 \mathrm{~h}$. Palmitate concentration was chosen on the basis of prior experiments performed in our laboratory [45]. Intracellular TG content was measured by enzymatic methods, as earlier described [45].

\subsection{Proliferation Assay}

The proliferation of HepG2 hepatocytes was determined by measuring the amount of thymidine analog bromodeoxyuridin (BrdU) incorporated into nuclear DNA with the BrdU cell proliferation assay (QIA58, Calbiochem, Darmstadt, Germany) following the 
manufacturer's instructions. The proliferative response was expressed as percentage of proliferation of treated cells compared to basal proliferation of unstimulated cells.

\subsection{Statistical Analysis}

Data are expressed as mean \pm SEM. Differences between mean values were determined using a Student's $t$-test, $\chi^{2}$ test, and two-way or one-way ANOVA followed by Scheffé's, Tukey's or Dunnet's tests, where appropriate. Pearson's correlation coefficients $(\mathrm{r})$ and stepwise multiple linear regression analysis were used to analyze the association between variables using age, sex and BMI as confounding factors. A $p$ value $<0.05$ was considered statistically significant. Statistical analyses were analyzed with SPSS 15.0.

Supplementary Materials: The following are available online at https://www.mdpi.com/article/10 $.3390 /$ ijms222312945/s1.

Author Contributions: Conceptualization, A.R. and G.F.; data curation, C.M.P., J.G.-A., S.B., V.V., R.M., E.M.F.-S., L.M.-G., S.E., V.C., C.S., J.E., G.F. and A.R.; formal analysis, C.M.P., J.G.-A., S.B., L.M.-G., S.E., V.C., G.F. and A.R.; writing—original draft preparation, A.R.; writing-review and editing, C.M.P., J.G.-A., S.B., V.C. and G.F.; supervision, A.R. and G.F.; project administration, A.R.; funding acquisition, A.R. and G.F. All authors have read and agreed to the published version of the manuscript.

Funding: This work was supported by Fondo de Investigación Sanitaria-FEDER (PI19/00785 and PI19/00990) from the Spanish Instituto de Salud Carlos III and the Department of Health of the Gobierno de Navarra (exp. 0011-3638-2020-000002). CIBER de Fisiopatología de la Obesidad y Nutrición (CIBEROBN) is an initiative of the Instituto de Salud Carlos III, Spain.

Institutional Review Board Statement: All reported investigations in volunteers and patients were carried out in accordance with the principles of the Declaration of Helsinki, as revised in 2013, and approved by the Ethical Committee of the Clínica Universidad de Navarra (protocol 2017.104, October 2017). All experimental protocols in animals were approved by the Ethical Committee for Animal Experimentation of the University of Navarra (049/10) and conformed to the European Guidelines for the Care and Use of Laboratory Animals (directive 2010/63/EU).

Informed Consent Statement: Informed consent was obtained from all the participants involved in the study (protocol 2017.104, October 2017).

Data Availability Statement: The data presented in this study are available on request from the corresponding author. The data are not publicly available due to privacy restrictions.

Acknowledgments: We gratefully acknowledge the technical assistance of Beatriz Ramírez, and the valuable collaboration of all the members of the Obesity Area, Clínica Universidad de Navarra, Pamplona, Spain. We also thank the collaboration of all the staff of the breeding house of the University of Navarra, in particular, Elena Ciordia, Alberto Espinal and Eneko Etxetxikia.

Conflicts of Interest: The authors declare no conflict of interest.

\section{References}

1. Powell, E.E.; Wong, V.W.; Rinella, M. Non-alcoholic fatty liver disease. Lancet 2021, 397, 2212-2224. [CrossRef]

2. Younossi, Z.; Anstee, Q.M.; Marietti, M.; Hardy, T.; Henry, L.; Eslam, M.; George, J.; Bugianesi, E. Global burden of NAFLD and NASH: Trends, predictions, risk factors and prevention. Nat. Rev. Gastroenterol. Hepatol. 2018, 15, 11-20. [CrossRef] [PubMed]

3. Machado, M.; Marques-Vidal, P.; Cortez-Pinto, H. Hepatic histology in obese patients undergoing bariatric surgery. J. Hepatol. 2006, 45, 600-606. [CrossRef] [PubMed]

4. Younossi, Z.M.; Golabi, P.; de Avila, L.; Paik, J.M.; Srishord, M.; Fukui, N.; Qiu, Y.; Burns, L.; Afendy, A.; Nader, F. The global epidemiology of NAFLD and NASH in patients with type 2 diabetes: A systematic review and meta-analysis. J. Hepatol. 2019, 71, 793-801. [CrossRef] [PubMed]

5. Cummings, D.E.; Rubino, F. Metabolic surgery for the treatment of type 2 diabetes in obese individuals. Diabetologia 2018, 61, 257-264. [CrossRef] [PubMed]

6. Mingrone, G.; Panunzi, S.; De Gaetano, A.; Guidone, C.; Iaconelli, A.; Capristo, E.; Chamseddine, G.; Bornstein, S.R.; Rubino, F. Metabolic surgery versus conventional medical therapy in patients with type 2 diabetes: 10-year follow-up of an open-label, single-centre, randomised controlled trial. Lancet 2021, 397, 293-304. [CrossRef] 
7. European Association for the Study of the Liver (EASL); European Association for the Study of Diabetes (EASD); European Association for the Study of Obesity (EASO). EASL-EASD-EASO Clinical Practice Guidelines for the management of non-alcoholic fatty liver disease. J. Hepatol. 2016, 64, 1388-1402. [CrossRef]

8. Lassailly, G.; Caiazzo, R.; Buob, D.; Pigeyre, M.; Verkindt, H.; Labreuche, J.; Raverdy, V.; Leteurtre, E.; Dharancy, S.; Louvet, A.; et al. Bariatric surgery reduces features of nonalcoholic steatohepatitis in morbidly obese patients. Gastroenterology 2015, 149, 379-388. [CrossRef]

9. Baldwin, D.; Chennakesavalu, M.; Gangemi, A. Systematic review and meta-analysis of Roux-en-Y gastric bypass against laparoscopic sleeve gastrectomy for amelioration of NAFLD using four criteria. Surg. Obes. Relat. Dis. 2019, 15, $2123-2130$. [CrossRef]

10. Zhang, R. Lipasin, a novel nutritionally-regulated liver-enriched factor that regulates serum triglyceride levels. Biochem. Biophys. Res. Commun. 2012, 424, 786-792. [CrossRef]

11. Wang, Y.; Quagliarini, F.; Gusarova, V.; Gromada, J.; Valenzuela, D.M.; Cohen, J.C.; Hobbs, H.H. Mice lacking ANGPTL8 (Betatrophin) manifest disrupted triglyceride metabolism without impaired glucose homeostasis. Proc. Natl. Acad. Sci. USA 2013, 110, 16109-16114. [CrossRef] [PubMed]

12. Zhang, L.; Shannon, C.E.; Bakewell, T.M.; Abdul-Ghani, M.A.; Fourcaudot, M.; Norton, L. Regulation of ANGPTL8 in liver and adipose tissue by nutritional and hormonal signals and its effect on glucose homeostasis in mice. Am. J. Physiol. Endocrinol. Metab. 2020, 318, E613-E624. [CrossRef] [PubMed]

13. Sylvers-Davie, K.L.; Davies, B.S.J. Regulation of lipoprotein metabolism by ANGPTL3, ANGPTL4, and ANGPTL8. Am. J. Physiol. Endocrinol. Metab. 2021, 321, E493-E508. [CrossRef]

14. Quagliarini, F.; Wang, Y.; Kozlitina, J.; Grishin, N.V.; Hyde, R.; Boerwinkle, E.; Valenzuela, D.M.; Murphy, A.J.; Cohen, J.C.; Hobbs, H.H. Atypical angiopoietin-like protein that regulates ANGPTL3. Proc. Natl. Acad. Sci. USA 2012, 109, 19751-19756. [CrossRef]

15. Alenad, A.; Alenezi, M.M.; Alokail, M.S.; Wani, K.; Mohammed, A.K.; Alnaami, A.M.; Sulimani, M.; Zargar, S.; Clerici, M.; Al-Daghri, N.M. Association of ANGPTL8 (betatrophin) gene variants with components of metabolic syndrome in Arab adults. Sci. Rep. 2020, 10, 6764. [CrossRef] [PubMed]

16. Peloso, G.M.; Auer, P.L.; Bis, J.C.; Voorman, A.; Morrison, A.C.; Stitziel, N.O.; Brody, J.A.; Khetarpal, S.A.; Crosby, J.R.; Fornage, M.; et al. Association of low-frequency and rare coding-sequence variants with blood lipids and coronary heart disease in 56,000 whites and blacks. Am. J. Hum. Genet. 2014, 94, 223-232. [CrossRef]

17. Barja-Fernández, S.; Folgueira, C.; Seoane, L.M.; Casanueva, F.F.; Dieguez, C.; Castelao, C.; Agüera, Z.; Banos, R.; Botella, C.; de la Torre, R.; et al. Circulating betatrophin levels are increased in anorexia and decreased in morbidly obese women. J. Clin. Endocrinol. Metab. 2015, 100, E1188-E1196. [CrossRef]

18. Gómez-Ambrosi, J.; Pascual, E.; Catalán, V.; Rodríguez, A.; Ramírez, B.; Silva, C.; Gil, M.J.; Salvador, J.; Frühbeck, G. Circulating betatrophin concentrations are decreased in human obesity and type 2 diabetes. J. Clin. Endocrinol. Metab. 2014, 99, E2004-E2009. [CrossRef]

19. Gómez-Ambrosi, J.; Pascual-Corrales, E.; Catalán, V.; Rodríguez, A.; Ramírez, B.; Romero, S.; Vila, N.; Ibañez, P.; Margall, M.A.; Silva, C.; et al. Altered concentrations in dyslipidemia evidence a role for ANGPTL8/betatrophin in lipid metabolism in humans. J. Clin. Endocrinol. Metab. 2016, 101, 3803-3811. [CrossRef]

20. Pascual-Corrales, E.; Gómez-Ambrosi, J.; Moncada, R.; Valentí, V.; Catalán, V.; Rodríguez, A.; Ramírez, B.; Silva, C.; Gil, M.J.; Salvador, J.; et al. Circulating ANGPTL8/betatrophin concentrations are increased after surgically induced weight loss, but not after diet-induced weight loss. Obes. Surg. 2016, 26, 1881-1889. [CrossRef]

21. Guo, C.; Wang, C.; Deng, X.; He, J.; Yang, L.; Yuan, G. ANGPTL8 in metabolic homeostasis: More friend than foe? Open Biol. 2021, 11, 210106. [CrossRef] [PubMed]

22. García-Monzón, C.; Petrov, P.D.; Rey, E.; Marañón, P.; Del Pozo-Maroto, E.; Guzmán, C.; Rodríguez de Cía, J.; Casado-Collado, A.J.; Vargas-Castrillón, J.; Saez, A.; et al. Angiopoietin-like protein 8 is a novel vitamin D receptor target gene involved in nonalcoholic fatty liver pathogenesis. Am. J. Pathol. 2018, 188, 2800-2810. [CrossRef] [PubMed]

23. Lee, Y.H.; Lee, S.G.; Lee, C.J.; Kim, S.H.; Song, Y.M.; Yoon, M.R.; Jeon, B.H.; Lee, J.H.; Lee, B.W.; Kang, E.S.; et al. Association between betatrophin/ANGPTL8 and non-alcoholic fatty liver disease: Animal and human studies. Sci. Rep. 2016, 6, 24013. [CrossRef] [PubMed]

24. Ke, Y.; Liu, S.; Zhang, Z.; Hu, J. Circulating angiopoietin-like proteins in metabolic-associated fatty liver disease: A systematic review and meta-analysis. Lipids Health Dis. 2021, 20, 55. [CrossRef] [PubMed]

25. von Loeffelholz, C.; Pfeiffer, A.F.H.; Lock, J.F.; Lieske, S.; Docke, S.; Murahovschi, V.; Kriebel, J.; de Las Heras Gala, T.; Grallert, H.; Rudovich, N.; et al. ANGPTL8 (Betatrophin) is Expressed in Visceral Adipose Tissue and Relates to Human Hepatic Steatosis in Two Independent Clinical Collectives. Horm. Metab. Res. 2017, 49, 343-349. [CrossRef] [PubMed]

26. Dang, F.; Wu, R.; Wang, P.; Wu, Y.; Azam, M.S.; Xu, Q.; Chen, Y.; Liu, Y. Fasting and feeding signals control the oscillatory expression of Angptl8 to modulate lipid metabolism. Sci. Rep. 2016, 6, 36926. [CrossRef]

27. Guo, C.; Zhao, Z.; Deng, X.; Chen, Z.; Tu, Z.; Yuan, G. Regulation of angiopoietin-like protein 8 expression under different nutritional and metabolic status. Endocr. J. 2019, 66, 1039-1046. [CrossRef]

28. Ren, G.; Kim, J.Y.; Smas, C.M. Identification of RIFL, a novel adipocyte-enriched insulin target gene with a role in lipid metabolism. Am. J. Physiol. Endocrinol. Metab. 2012, 303, E334-E351. [CrossRef]

29. Müller, F.A.; Sturla, S.J. Human in vitro models of nonalcoholic fatty liver disease. Curr. Opin. Toxicol. 2019, 16, 9-16. [CrossRef] 
30. Hu, W.; Shao, X.; Guo, D.; Hao, H.; Zhang, Y.; Xia, M.; Gong, Y.; Zhou, H.; Fan, Y.; Yu, W. Relationship of Serum Betatrophin with Nonalcoholic Fatty Liver in a Chinese Population. PLoS ONE 2017, 12, e0170758. [CrossRef]

31. Hong, B.S.; Liu, J.; Zheng, J.; Ke, W.; Huang, Z.; Wan, X.; He, X.; Xiao, H.; Li, Y. Angiopoietin-like protein 8/betatrophin correlates with hepatocellular lipid content independent of insulin resistance in non-alcoholic fatty liver disease patients. J. Diabetes Investig. 2018, 9, 952-958. [CrossRef]

32. Cengiz, M.; Ozenirler, S.; Kocabiyik, M. Serum beta-trophin level as a new marker for noninvasive assessment of nonalcoholic fatty liver disease and liver fibrosis. Eur. J. Gastroenterol. Hepatol. 2016, 28, 57-63. [CrossRef]

33. Fenzl, A.; Itariu, B.K.; Kosi, L.; Fritzer-Szekeres, M.; Kautzky-Willer, A.; Stulnig, T.M.; Kiefer, F.W. Circulating betatrophin correlates with atherogenic lipid profiles but not with glucose and insulin levels in insulin-resistant individuals. Diabetologia 2014, 57, 1204-1208. [CrossRef]

34. de Brito, E.S.M.B.; Tustumi, F.; de Miranda Neto, A.A.; Dantas, A.C.B.; Santo, M.A.; Cecconello, I. Gastric bypass compared with sleeve gastrectomy for nonalcoholic fatty liver disease: A systematic review and meta-analysis. Obes. Surg. 2021, 31, $2762-2772$. [CrossRef] [PubMed]

35. Cherla, D.V.; Rodriguez, N.A.; Vangoitsenhoven, R.; Singh, T.; Mehta, N.; McCullough, A.J.; Brethauer, S.A.; Schauer, P.R.; Aminian, A. Impact of sleeve gastrectomy and Roux-en-Y gastric bypass on biopsy-proven non-alcoholic fatty liver disease. Surg. Endosc. 2020, 34, 2266-2272. [CrossRef] [PubMed]

36. Faramia, J.; Ostinelli, G.; Drolet-Labelle, V.; Picard, F.; Tchernof, A. Metabolic adaptations after bariatric surgery: Adipokines, myokines and hepatokines. Curr. Opin. Pharmacol. 2020, 52, 67-74. [CrossRef] [PubMed]

37. Gómez-Ambrosi, J.; Gallego-Escuredo, J.M.; Catalán, V.; Rodríguez, A.; Domingo, P.; Moncada, R.; Valentí, V.; Salvador, J.; Giralt, M.; Villarroya, F.; et al. FGF19 and FGF21 serum concentrations in human obesity and type 2 diabetes behave differently after diet- or surgically-induced weight loss. Clin. Nutr. 2017, 36, 861-868. [CrossRef]

38. Poloczek, J.; Kazura, W.; Kwasnicka, E.; Gumprecht, J.; Jochem, J.; Stygar, D. Effects of bariatric surgeries on fetuin-A, selenoprotein P, angiopoietin-like protein 6, and fibroblast growth factor 21 concentration. J. Diabetes Res. 2021, 2021, 5527107. [CrossRef] [PubMed]

39. Al-Shawaf, E.; Al-Ozairi, E.; Al-Asfar, F.; Al-Beloushi, S.; Kumari, S.; Tuomilehto, J.; Arefanian, H. Biphasic changes in angiopoietinlike 8 level after laparoscopic sleeve gastrectomy and type 2 diabetes remission during a 1-year follow-up. Surg. Obes. Relat. Dis. 2018, 14, 1284-1294. [CrossRef]

40. Guo, K.; Yu, H.; Lu, J.; Bao, Y.; Chen, H.; Jia, W. Decreased serum betatrophin levels correlate with improved fasting plasma glucose and insulin secretion capacity after Roux-en-Y gastric bypass in obese Chinese patients with type 2 diabetes: A 1-year follow-up. Surg. Obes. Relat. Dis. 2016, 12, 1343-1348. [CrossRef]

41. Song, Z.; Guo, K.; Huang, W.; Xu, H.; Liu, Y.; Guan, J.; Yin, S.; Yu, H.; Yi, H.; Zou, J. Decreased serum betatrophin may correlate with the improvement of obstructive sleep apnea after Roux-en-Y Gastric Bypass surgery. Sci. Rep. 2021, 11, 1808. [CrossRef] [PubMed]

42. Ejarque, M.; Borlaug, M.; Vilarrasa, N.; Martinez-Perez, B.; Llauradó, G.; Megía, A.; Helland, T.; Gutierrez, C.; Serena, C.; Folkestad, O.; et al. Angiopoietin-like protein 8/betatrophin as a new determinant of type 2 diabetes remission after bariatric surgery. Transl. Res. 2017, 184, 35-44.e4. [CrossRef] [PubMed]

43. American Diabetes Association. 2. Classification and Diagnosis of Diabetes: Standards of Medical Care in Diabetes-2021. Diabetes Care 2021, 44, S15-S33. [CrossRef]

44. Kleiner, D.E.; Brunt, E.M.; Van Natta, M.; Behling, C.; Contos, M.J.; Cummings, O.W.; Ferrell, L.D.; Liu, Y.C.; Torbenson, M.S.; Unalp-Arida, A.; et al. Design and validation of a histological scoring system for nonalcoholic fatty liver disease. Hepatology 2005, 41, 1313-1321. [CrossRef]

45. Ezquerro, S.; Becerril, S.; Tuero, C.; Méndez-Giménez, L.; Mocha, F.; Moncada, R.; Valentí, V.; Cienfuegos, J.A.; Catalán, V.; Gómez-Ambrosi, J.; et al. Role of ghrelin isoforms in the mitigation of hepatic inflammation, mitochondrial dysfunction, and endoplasmic reticulum stress after bariatric surgery in rats. Int. J. Obes. 2020, 44, 475-487. [CrossRef] [PubMed]

46. Ezquerro, S.; Mocha, F.; Frühbeck, G.; Guzmán-Ruiz, R.; Valentí, V.; Mugueta, C.; Becerril, S.; Catalán, V.; Gómez-Ambrosi, J.; Silva, C.; et al. Ghrelin reduces TNF-alpha-induced human hepatocyte apoptosis, autophagy, and pyroptosis: Role in obesity-associated NAFLD. J. Clin. Endocr. Metab. 2019, 104, 21-37. [CrossRef] [PubMed]

47. Unamuno, X.; Gómez-Ambrosi, J.; Ramírez, B.; Rodríguez, A.; Becerril, S.; Valentí, V.; Moncada, R.; Silva, C.; Salvador, J.; Frühbeck, G.; et al. NLRP3 inflammasome blockade reduces adipose tissue inflammation and extracellular matrix remodeling. Cell. Mol. Immunol. 2021, 18, 1045-1057. [CrossRef] 